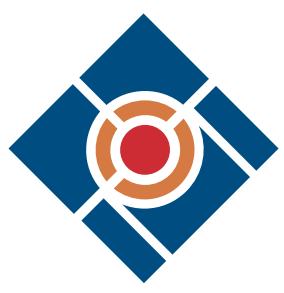

Methane pyrolysis is an up-scalable technology that produces hydrogen as a lower carbon-intensity energy carrier and industrial feedstock. This technology can attract more investment for lower-carbon intensity hydrogen if co-produced solid carbon (potentially hundreds of million tons per year) has value-added applications. The solid carbon can be permanently stored in concrete, the second most used commodity worldwide. To understand the feasibility of this carbon storage strategy, up to $10 \mathrm{wt} \%$ of Portland cement is replaced with disk-like or fibrillar carbon in our study. The incorporation of $5 \%$ and $10 \%$ fibrillar carbons increase the compressive strength of the cement-based materials by at least $20 \%$ and $16 \%$, respectively, while disk-like carbons have little beneficial effects on the compressive strength. Our life-cycle assessment in climate change category results suggest that the $10 \%$ cement replacement with the solid carbon can lower $\sim 10 \%$ of greenhouse gas emissions of cement production, which is currently the second-largest industrial emitter in the world. The use of solid carbon in concrete can supplement the enormous demand for cement substitute for low-carbon concrete and lower the cost of the low-carbon hydrogen production. This massively available low-cost solid carbon would create numerous new opportunities in concrete research and the industrial applications.

\title{
Sequestration of solid carbon in concrete: A large-scale enabler of lower-carbon intensity hydrogen from natural gas
}

\author{
Jiaqi Li, Leonardo Spanu, Jeffrey Heo, Wenxin Zhang, \\ David W. Gardner, Carlo Carraro, Roya Maboudian, and \\ Paulo J.M. Monteiro*
}

Methane pyrolysis is an emerging technology to produce lower-carbon intensity hydrogen at scale, as long as the co-produced solid carbon is permanently captured. Partially replacing Portland cement with pyrolytic carbon would allow the sequestration at a scale that matches the needs of the $\mathrm{H}_{2}$ industry. Our results suggest that compressive strength, the most critical mechanical property, of blended cement could even be improved while the cement manufacture, which contributes to $\sim 9 \%$ global anthropogenic $\mathrm{CO}_{2}$ emissions, can be decarbonized. $\mathrm{A} \mathrm{CO}_{2}$ abatement up to $10 \%$ of cement production could be achieved with the inclusion of selected carbon morphologies, without the need of significant capital investment and radical modification of current production processes. The use of solid carbon could have a higher $\mathrm{CO}_{2}$ abatement potential than the incorporation of conventional industrial wastes used in concrete at the same replacement level. With this approach, the concrete industry could become an enabler for manufacturing a lower-carbon intensity hydrogen in a win-win solution.

\section{Introduction}

In a methane pyrolysis process, methane molecules are split into solid carbon and gaseous hydrogen without $\mathrm{CO}_{2}$ emissions associated to the reaction. ${ }^{1}$ The technology is an emerging option to produce hydrogen at lower carbon intensity than the currently mostly used process (i.e., steam methane reforming), if the solid carbon produced is sequestered in a permanent form. ${ }^{2}$ Since the mass of produced solid carbon is three times the mass of hydrogen, finding an outlet for the solid carbon is critical for large-scale deployment of the technology.

Current hydrogen market is $\sim 70 \mathrm{Mt} /$ year and projected to grow in the coming decades: ${ }^{3}$ if methane pyrolysis took over overnight, it would require a market for solid carbon of $\sim 210 \mathrm{Mt} /$ year. If we exclude metallurgical applications, the current combined market for carbon materials does not match such scale. In metallurgical applications (e.g., steel and aluminum), the solid carbon is in fact used

Jiaqi Li, Department of Civil and Environmental Engineering, University of California, USA

Leonardo Spanu, Shell International Exploration \& Production Inc, USA

Jeffrey Heo, Department of Chemical and Biomolecular Engineering, University of California, USA

Wenxin Zhang, Department of Civil and Environmental Engineering, University of California, USA

David W. Gardner, Department of Chemical and Biomolecular Engineering, University of California, USA

Carlo Carraro, Department of Chemical and Biomolecular Engineering, University of California, USA

Roya Maboudian, Department of Chemical and Biomolecular Engineering, University of California, USA

Paulo J.M. Monteiro, Department of Civil and Environmental Engineering, University of California, USA;

monteiro@berkeley.edu

*Corresponding author

doi:10.1557/s43577-021-00118-z 
as reducing agent for metal ores and is converted into $\mathrm{CO}_{2}$ : although the market size for metallurgical carbon is significant ( $\sim 650 \mathrm{Mt} /$ year for metallurgical coke and $\sim 23 \mathrm{Mt} /$ year of calcinable coke), ${ }^{4}$ such carbon applications would not qualify as a sequestration form.

The building industry is the only sector that could rival in market size (tonnages of material per year) to the energy industry and could match a potential market for pyrolytic carbon. ${ }^{5}$ The use of carbon in structural applications (and building in general) is, however, limited. Although carbon-based composites materials are emerging options in the building sector, concrete and steel remain the dominant materials, with limited credible alternatives at scale. The full replacement of concrete with carbon materials derived from methane seems unlikely in the coming decades. The incorporation in concrete of carbon materials from methane pyrolysis is, however, a more achievable goal in the short term. By replacing a portion of the clinker (the main component of Portland cement) ${ }^{6}$ in the cement formulation, we could support a partial decarbonization of two hard-to-abate sectors: hydrogen production ${ }^{2}$ and cement manufacturing ${ }^{7}$ (see Figure 1). The sequestration of solid carbon in cement would provide a viable solution for the utilization of the carbon from methane pyrolysis, enabling the potential deployment of this lower greenhouse gas (GHG) technology at scale. On the other hand, the inclusion of solid carbon in the cement formulation would allow a partial reduction of the overall GHG intensity of the final concrete, with potential added benefits to the mechanical and electrical properties of the final concrete products. The partial replacement

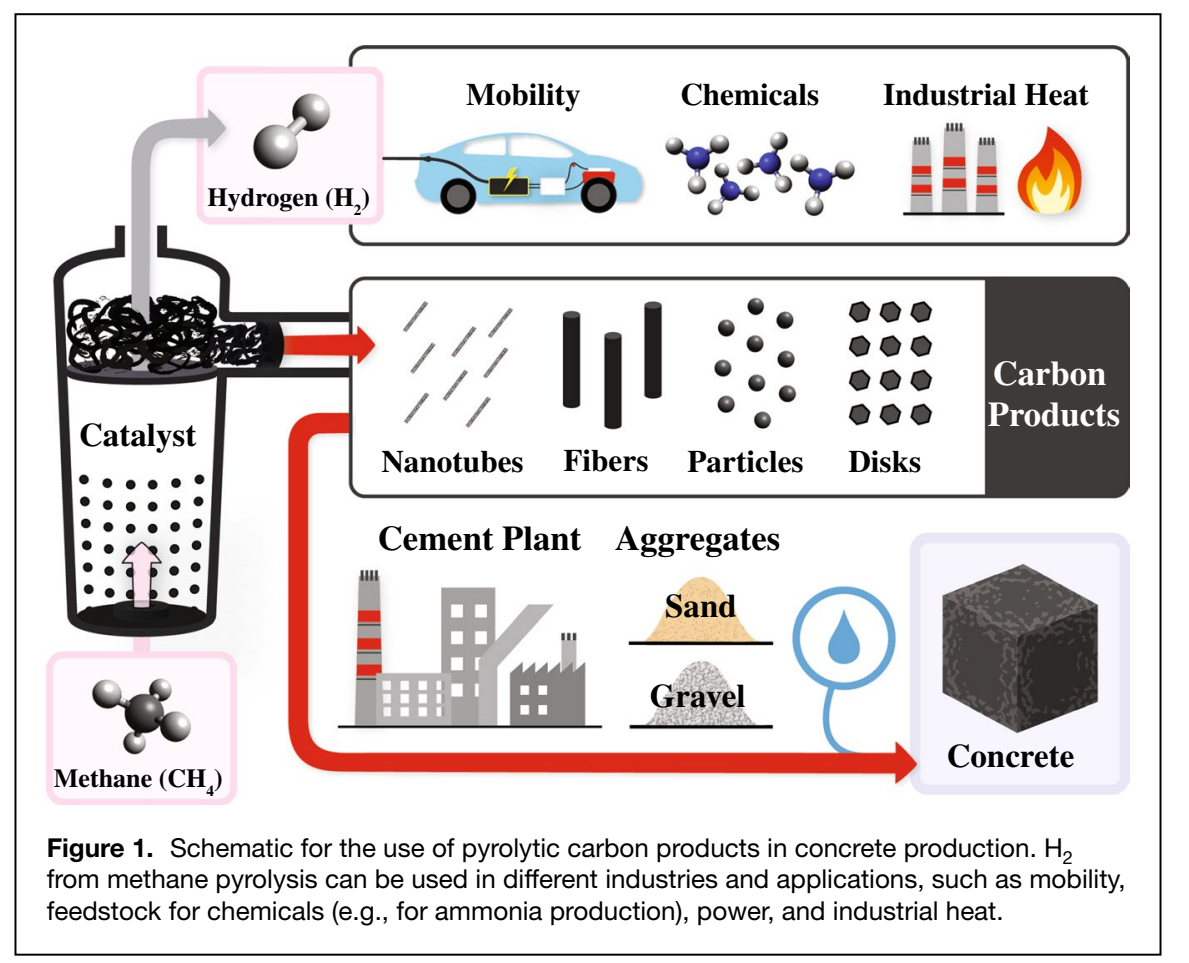

of the clinker with products from other industries is not a new approach in the cement industry and would fit well into the decarbonization goals of the broader building industry. ${ }^{8}$

In this study, we discuss the inclusion of carbon archetypes with different morphologies into cement, analyzing the impact on final mechanical properties, workability, and GHG footprint. We have focused on carbon materials in the micron + range size, to allow for higher replacement of cement (up to $10 \mathrm{wt} \%$ ) and an easier dispersion. This is a critical difference from past investigations on carbon nano-materials in cement, ${ }^{9}$ where the amount of carbon (as an addition) is limited to a fraction of wt $\%$ (to avoid the negative impact on the desirable rheological properties) and the use of nanomaterials can be hazardous to builders. Our overall goal is in fact to capture a large fraction of solid pyrolytic carbon in cement, without affecting performance or perhaps even improving it. This study aims to alert the cement-energy community of an exciting possibility of reducing the carbon footprint of the two industrial sectors and tailoring the morphology of byproduct carbon from methane pyrolysis.

\section{Results and discussion}

We have considered the partial replacement of clinker with two different morphologies - carbon disks and fibers-as potential archetypes of carbon materials derived from methane pyrolysis. We have focused our analysis on both performance of the cement after the carbon inclusion and impact of the carbon inclusion on the GHG footprint (climate change category) of concrete production. To be adopted by the concrete industry, any novel solutions should provide a performance or cost benefit (or at least not be detrimental) and support the decarbonization goals of the broader industry.

We have first evaluated the influence of the carbon inclusion on the water required for the binder paste. The water content affects the consistency of the binder (see the Methods section) and overall workability (e.g., flowability). In Figure 2a, we have summarized the results for water requirement (expressed in water-tobinder mass ratio (w/b)) as a function of the carbon substitution levels. For both carbon disks and carbon fibers we observe an increase in the water demand with increasing level of carbon in the paste. The increase in water demand is commonly found in pastes incorporating fine materials, such as silica fume and rice husk ash. ${ }^{10}$ Although disks and fibers show similar trends in water requirement, 

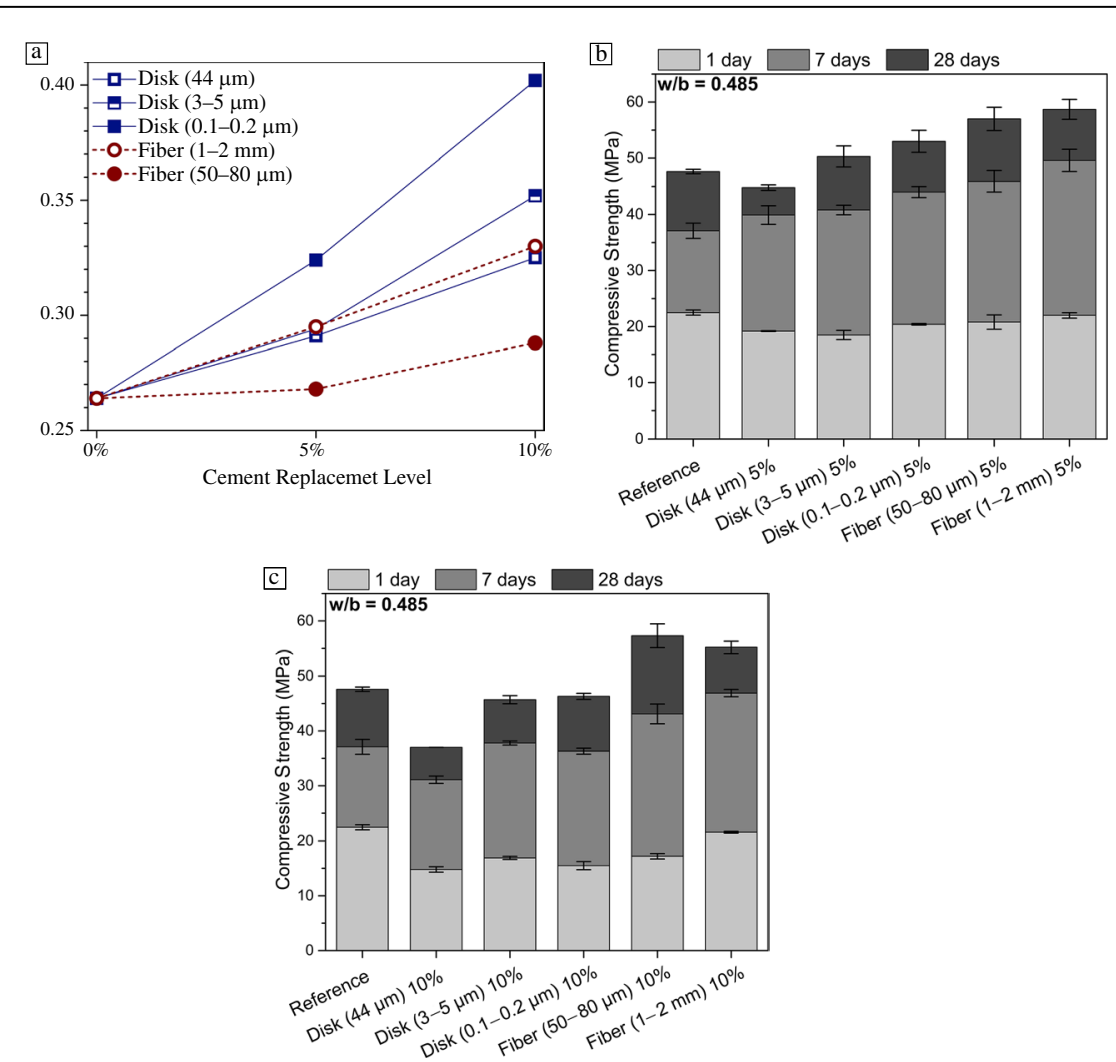

Figure 2. (a) Water demand (water-to-binder ratio (w/b)) for pastes with normal consistency (see the Method section for definition) as a function of cement replacement levels. Uniaxial compressive strength of mortar at different ages with cement replacement level of (b) $5 \%$ and (c) $10 \%$. The disk diameter and fiber length are indicated in parentheses.

can improve concrete workability but would lower the concrete strength or increase the material cost, respectively. As shown in Figure 2a, the partial replacement of cement with carbon materials increases the water demand. It follows that a low dosage of superplasticizer (surfactant, e.g., polycarboxylate ether (PCE) $)^{15}$ is needed to improve the workability without additional water or paste for construction efficiency. ${ }^{16} \mathrm{PCE}$ is widely used in concrete production when high workability is required. Note that, the use of $\mathrm{PCE}$ slightly retards the cement hydration at the early age, typically up to 1 day, ${ }^{15,16-18}$ but negligibly influences long-term binder strength.

To evaluate the binders' mechanical properties, mortar samples were cast by blending paste with pure quartz sand. At the cement replacement level of $5 \mathrm{wt} \%$, all the carbon-incorporated mortars exhibited slightly lower uniaxial compressive strengths at 1 day than the reference group due to the lower cement content and $\mathrm{PCE}$-induced retardation of cement hydration ${ }^{16}$ (Figure $2 b$ ). As the cement hydrates over time, the

the explanations of such behavior are different. Carbon disks tend to increase the binder's surface area, and the water demand increases as the binder incorporates more finer disks. In contrast, longer fibers reduce the flowability of pastes; thus, binders containing longer fibers require more water than the mix with shorter fibers to maintain the normal consistency and appropriate paste flowability (see Supplementary information). In both cases, however, water content needs to be increased to keep a normal consistency ${ }^{11}$ (i.e., to maintain a constant penetration depth, see the Methods section), and the water demand of binder increases at higher carbon content.

The inverse relationship between strength and porosity of solids is well known. More water than needed for the cement hydration leaves voids when the paste is hardened. ${ }^{12}$ Higher $\mathrm{w} / \mathrm{b}$ ratios result in higher porosity in hardened pastes and thus lower strength of cement-based materials (e.g., concrete). ${ }^{6}$ When the paste content or w/b ratio is low, the workability (e.g., flowability) of concrete is poor, which typically leads to low construction efficiency and defects in concrete. The defects usually result in concrete's low strength and poor durability (e.g., steel-rebar corrosion). ${ }^{13,14}$ Adding additional water or paste in concrete strength of mortar increases. After 7 days, at the replacement level of $5 \mathrm{wt} \%$, the group incorporated with coarse carbon disks $(44 \mu \mathrm{m})$ still exhibited lower strengths than the reference, while the finer disks slightly increased the compressive strengths. The disks have no binding properties, and coarser disks decrease the packing density of the mortar matrix: disks with $44 \mu \mathrm{m}$ diameter are coarser than cement particles (median value of $11 \mu \mathrm{m}$ ). The disks with $0.1-5 \mu \mathrm{m}$ diameters are finer than cement particles, thus filling the pores between cement grains and increasing the compacting density of the mortars. Compared to the reference group, carbon fibers increase the mortar strength from 7 days, because fibers can bridge microcracks within the mortar matrix and limit crack propagation during loading. This "tape"-like role of carbon fibers in cement-based materials is also found in many other fiber reinforced cement composites. $^{18}$

At the replacement level of $10 \mathrm{wt} \%$, the strengths are lower than those at replacement levels of $5 \mathrm{wt} \%$ at 1 day (Figure 2c). We hypothesize that this is due to lower cement content and PCE-induced retardation in cement hydration caused at the higher replacement level. High PCE dosage is known to retard 
cement hydration therefore, slightly lowering the early-age strength of cement-based materials. ${ }^{16,19}$ The strengths of mortar with coarser disks from 7 days are $\sim 20 \%$ lower than the reference due to the low cement content and the lack of the aforementioned pore-filling effect. The strengths of mortar with finer disks from 7 days are similar to the reference as the pore-filling effect of finer disk compensates the negative effect of low cement content. Carbon fibers still slightly increase the mortar strength from $7+$ days at the cement replacement level of $10 \mathrm{wt} \%$ due to the beneficial microcrack-bridging effect. ${ }^{18}$ Carbon materials, such as carbon fibers and carbon black nano powders, have been used as additions, instead of cement substitutes, in concrete for reinforcement or selfsensing properties. For instance, carbon fiber reinforced cement composites exhibit high tensile strength and ductility. The addition of microfibers in cement-based materials also increases the compressive strength. ${ }^{20-22}$ The addition of nano carbon black typically lowers the mechanical properties but increases the electrical conductivity of cement composites. ${ }^{23}$ These cement-carbon composites are more expensive than plain concrete without any carbon inclusion, and hence only target specific niche markets. In the present study, the partial cement replacement with byproduct carbon aims for higher or comparable compressive strength (the most important mechanical property) than plain concrete without carbon inclusion. If this cement replacement also results in lower or comparable cost, this carbon inclusion can target a much larger market in a scale of hundreds of Mt/year.

For the GHG footprint we have focused on a Californiabased scenario, expressing the GHG emissions (e.g., $\mathrm{CO}_{2}$, $\mathrm{CH}_{4}$; mainly $\left.\mathrm{CO}_{2}\right)$ in $\mathrm{CO}_{2}$-equivalent $\left(\mathrm{CO}_{2}\right.$-e). The influence of carbon on the GHG emissions on binder in California-based scenario is compared to the scenarios in Texas and Florida later. The three states are the largest cement consumer in the United States. The low-carbon intensity industrial byproducts, fly ash from coal-fired power plants and blast-furnace slag from pig-iron making, are commonly used to partially replace cement. ${ }^{8}$ The upper limit of cement replacement with amorphous silicates (e.g., fly ash and blast-furnace slag) is typically $35 \mathrm{wt} \%$, while the cement replacement level with inert materials is limited to $5-10 \mathrm{wt}$ percent. Note that there has been a global shortage (hundreds of $\mathrm{Mt} /$ year) of blast-furnace slag and high-grade fly ash (e.g., limited toxic element content) for their use in concrete production. ${ }^{8}$ There would be no competition between solid carbon and fly ash/slag as cement substitutes if hundreds of Mt/year of pyrolytic carbons are available. Considering the current decommissioning of coalfired power plants and increasing demand for cement, the shortage of cement substitutes would be even higher, particularly in regions with a limited supply of fly ash or slag (e.g., California). Here, the influence of carbon, the byproduct from methane pyrolysis, on the GHG emissions of binder production is compared with that of fly ash and blast-furnace slag at cement replacement level of 5-10 wt $\%$ (see a California-based scenario in Figure 3).
In the California-based scenario, cement production dominates the total GHG emissions of the production/processing/ transportation of binders and PCE superplasticizer (Figure 3a). Thus, the $10 \%$ cement replacement level dominates the GHG emission reduction. The emissions from cement substitutes (fly ash, slag, and solid carbon) and PCE are below 4\% in total. The slight variation in GHG emissions is due to the different carbon intensity of processing and transportation distance of fly ash and slag. In addition, the partial replacement of cement with fly ash and slag typically needs no PCE for maintaining sufficient workability. The cement replacement at $10 \mathrm{wt} \%$ with the three substitutes all results in $\sim 0.1 \mathrm{~kg} \mathrm{CO}_{2}$-e/kg binder of $\mathrm{GHG}$ reductions compared to the baseline group (i.e., no cement replacement). This GHG reduction shown in Figure 3a is expressed as binder saving in Figure $3 b$. The contribution of landfill saving (i.e., avoiding landfill of the three substitutes) of blended binders in GHG reductions is negligible $(<0.3 \%$ of $\mathrm{kg}$ binder) as the GHG emission of landfill processing is low and landfill transportation distance is typically short, ${ }^{24}$ modeled as $50 \mathrm{~km}$ here.

$\mathrm{CO}_{2}$ contributes to nearly $99 \%$ of the GHG emissions (overall $\mathrm{CO}_{2}$-e) during cement manufacture while the contributions of $\mathrm{CH}_{4}$ emissions are negligible. ${ }^{25}$ Hydrated cement is known to uptake $\mathrm{CO}_{2}$ and $\mathrm{NO}_{\mathrm{x}}$, but not $\mathrm{CH}_{4}$. Hydrated cement reacts with atmospheric $\mathrm{CO}_{2}$ during the service life of concrete, forming $\mathrm{CaCO}_{3}$. The high $\mathrm{CaO}$ content, typically over $60 \mathrm{wt} \%$, in Portland cement theoretically results in $\sim 50 \mathrm{wt} \%$ $\mathrm{CO}_{2}$ uptake. ${ }^{6}$ However, full carbonation of cement during the full life cycle of concrete (including service life and recycling) is rare, the maximum $\mathrm{CO}_{2}$ uptakes during the service life and after recycling are just $\sim 10 \%$ and $\sim 20 \%$, respectively. ${ }^{26}$ The $10 \%$ of cement replacement has insignificant influences on the potential of binder $\mathrm{CO}_{2}$ uptake because the cement substitute level is low and fly ash (0-30 wt $\% \mathrm{CaO}$ and $\mathrm{MgO})$ and blastfurnace slag $(\sim 50 \mathrm{wt} \% \mathrm{CaO}$ and $\mathrm{MgO})$ can be carbonated. Note that excessive carbonation of binder is detrimental to steel-reinforced concrete structures as carbonation lowers the $\mathrm{pH}$ of concrete matrix, de-passivates the surface of steel reinforcement, and triggers the risk of corrosion. ${ }^{8}$

The solid carbon storage has no such detrimental effects on steel-reinforced concrete. The solid carbon storage is in a permanent form during the service life of cement-based materials as no phase in cement oxidizes solid carbon. Solid carbon storage of $12 \mathrm{~g}$ equals to $44 \mathrm{~g}$ of $\mathrm{CO}_{2}$ storage. The instant storage of $\mathrm{CO}_{2}$ in the form of solid carbon at $10 \mathrm{wt} \%$ cement replacement level is $\sim 37 \mathrm{wt} \%$ of binder (Figure $3 \mathrm{~b}$ ), which is nearly twofold the full life-cycle storage of $\mathrm{CO}_{2}$, maximally $20 \mathrm{wt} \%$, of binder in the form of carbonated cement (i.e., $\mathrm{CaCO}_{3}$ ). It is worth mentioning that the solid carbon storage cannot be credited as GHG reduction to the carbon incorporated binders as landfilling the solid carbon also results in this solid carbon storage.

The net saving (i.e., the binder GHG reduction in Figure 3a plus the landfill saving) of GHG emissions of binder replacement with $10 \mathrm{wt} \%$ carbon shows its sensitivity (Figure $3 \mathrm{~b}$ ) to 


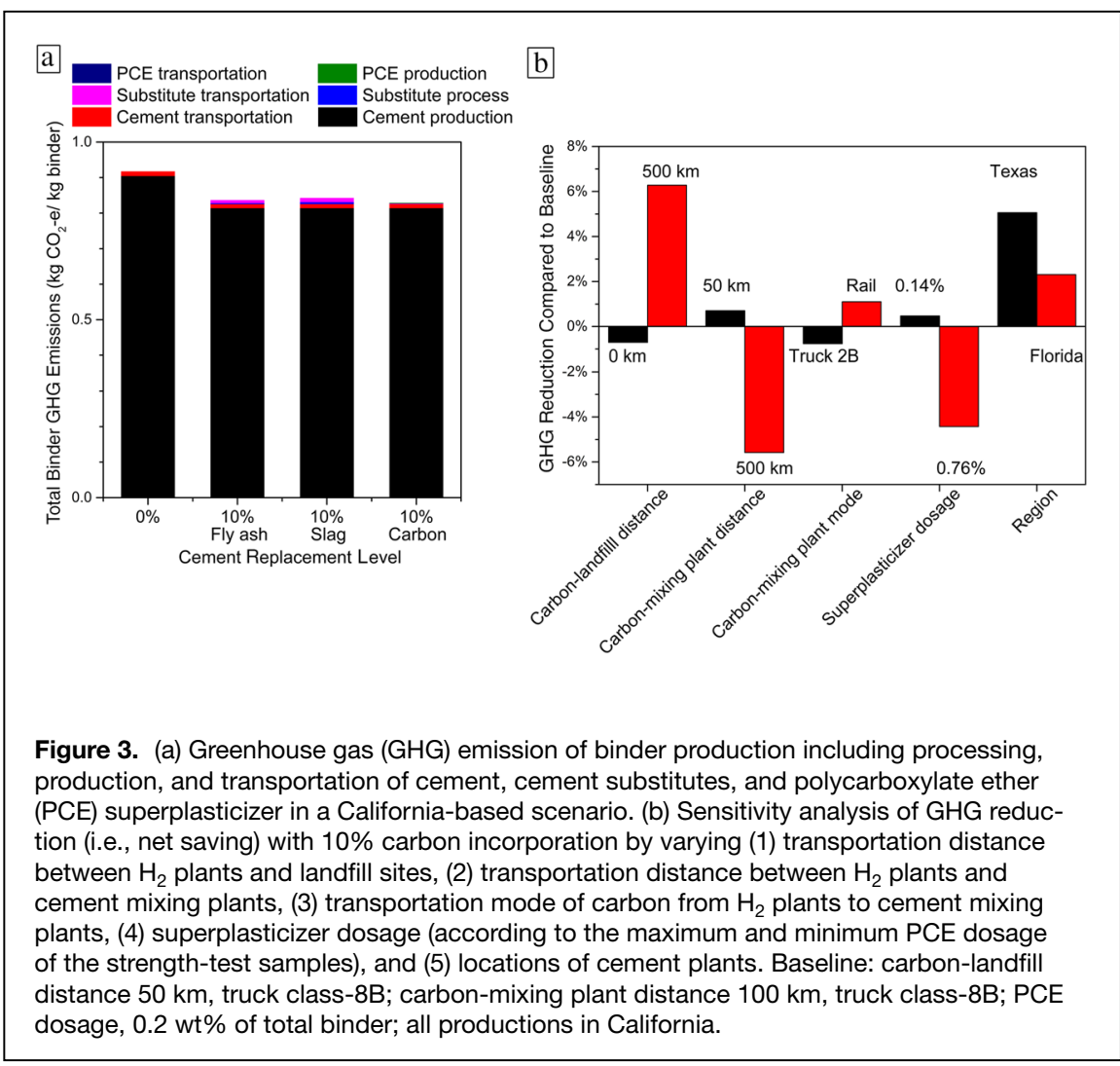

processing, if any, of the solid carbon from methane pyrolysis should be considered in climate change category in the life-cycle assessment of concrete production in future studies.

\section{Conclusions and path forward}

In this study, we have described a potential pathway for sequestering solid carbon materials from methane pyrolysis in a (semi)permanent way by including the carbon into cement formulation. This solid carbon can be permanently stored in concrete if carbon-incorporated concrete is recycled after the service life (e.g., 50 years) and reused in new concrete production. The proposed solution would be advantageous for two different industries-hydrogen and cement-both looking into decarbonization options and with similar material scales. We have analyzed the inclusion of morphologically different solid carbons, as potential archetypes of materials derived from methane pyrolysis. The analysis is far from being conclusive, but our

carbon transportation to cement mixing plants, the regional difference in the carbon intensity of cement production, and the dosage of superplasticizer. Its high sensitivity to PCE dosage is due to the carbon-intense manufacturing of PCE $\left(\sim 0.77 \mathrm{~kg} \mathrm{CO}_{2}\right.$-e/ kg PCE) ${ }^{25}$ The use of carbon in Texas and Florida results in a more pronounced GHG reduction because the cement production in these regions has a higher carbon intensity, due to the higher carbon intensity of electricity from the grid.

If the pyrolysis reactor is powered by electricity, the carbon intensity of the process depends on the carbon intensity of the electricity grid. Regional differences in the carbon intensity of the pyrolyzed hydrogen and carbon are expected. It is worth mentioning that the pyrolysis process might be carbon neutral if the reactor is fully powered by renewable energy. It could potentially become a negative carbon sink, if biogas (from organic matter) is used as a feedstock of the pyrolysis process. In the present study, solid carbon is considered as a waste, thus without embedded GHG emissions. As an industrial byproduct at scale, the allocation of embedded GHG emissions of solid carbon may be reconsidered. The embedded GHG emissions of industrial byproducts coal fly ash and blast-furnace slag in concrete production are not zero due to their collection and processing consume electricity. Further separation and preliminary findings are encouraging and could create multiple research avenues in both methane pyrolysis and concrete fields.

A future direction of exploration is to correlate the chemistry and morphology of specific carbon materials to final concrete performance, so as to guide the selection of relevant process conditions during the methane pyrolysis process. For a given morphology (i.e., disks, fibers, etc.), further optimization is needed to improve their final performance in the concrete. For example, coarse carbon disks would lower concrete strengths, while ultrafine disks would require higher superplasticizer dosage during concrete production, with negative impact on the removal time of concrete formwork. The disk's size distribution should be tuned for improving the packing density of the binder matrix. Although fibrous carbon materials could provide mechanical benefit, the optimal length and aspect ratio remain unknown. For example, the use of extra-long fibers in concrete would result in workability issues. The carbon surface can be potentially functionalized for improving the binder-carbon interaction. Further topics of investigation include the impacts of carbon on concrete aging, potential mitigation of rebar corrosion, effect on electrical conductivity and electromagnetic shielding, and overall appearance (Figure S1). 


\section{Materials}

White Portland cement with $57.3 \%$ alite, $30.1 \%$ belite, $4.6 \%$ tricalcium aluminate, and $3.1 \%$ calcium sulfates was used. The specific surface area (SSA) and median particle size of the cement are $1.2 \mathrm{~m}^{2} / \mathrm{g}$ and $10.9 \mu \mathrm{m}$, respectively. Instead of grey ordinary Portland cement, white cement was used in this proof-of-concept experiment because white cement showed distinct contrast with black carbon materials and could be useful to validate the dispersion of carbon in the mixes. White cement is known to show similar mechanical and chemical behavior compared to ordinary Portland cement. ${ }^{12}$ Two types of carbons, as the archetypes, were used to partially replace cement: (1) chopped polyacrylonitrile (PAN)-based carbon fibers $(96 \%+$ carbon content, Dighen, China) with a median diameter (D) of 6-7 $\mu \mathrm{m}$ and a nominal length of (L) of 1-2 $\mathrm{mm}$, and $\mathrm{D}=6-7 \mu \mathrm{m}$ and $\mathrm{L}=50-80 \mu \mathrm{m}$; and (2) processed natural graphite disks ( $99 \%$ + purity, Asbury, United States) with $\mathrm{D}=44 \mu \mathrm{m}\left(3.8 \mathrm{~m}^{2} / \mathrm{g}\right.$, thickness $\left.1-50 \mu \mathrm{m}\right), \mathrm{D}=3-5 \mu \mathrm{m}$ (SSA $16.7 \mathrm{~m}^{2} / \mathrm{g}$, thickness $\sim 300 \mathrm{~nm}$ ), and $\mathrm{D}=0.1-0.2 \mu \mathrm{m}$ (SSA $180 \mathrm{~m}^{2} / \mathrm{g}$, thickness $\sim 40 \mathrm{~nm}$ ). The fibers are straight with no extra modification of the surface functionality. The tensile modulus and strain capacity are $235 \mathrm{GPa}$ and $1.52 \%$, respectively. Deionized water was used to prepare paste and mortar. \#30-100 grade standard quartz sand (0.15-0.6 mm sieve size) was used in mortar preparation. The 50-mm mortar cubes with a sand-to-cement mass ratio of 2.75 were cured at $24^{\circ} \mathrm{C}$ at $100 \%$ relative humidity for different durations until strength measurement. A polycarboxylate ether-based superplasticizer solution ( $40 \mathrm{wt} \%$ solid content, BASF) was used to adjust the required workability of both pastes and mortars when necessary. The maximum superplasticizer solid dosage of the samples was $0.35 \mathrm{wt} \%$ of the binder.

\section{Methods}

The water demands for normal consistency of different binder mixes were determined according to ASTM C187. ${ }^{11}$ Water demand for normal consistency was defined as the water content that permits a Vicat plunger to penetrate a paste by 9-11 mm depth during $30 \mathrm{~s}$ of settling after completion of mixing. For uniaxial compressive strength measurement, three mortar cubes in each group were loaded at a rate of $0.5 \mathrm{MPa} / \mathrm{s}$.

The goal of the life cycle assessment (LCA) is to compare the GHG emissions (climate change category) of binders incorporated with carbon and other industrial byproducts (fly ash and blast-furnace slag). The life cycle model built on ISO 14,044 includes the acquisition of cement raw materials and the production, processing, and transportation of materials. The functional unit in the LCA is $1 \mathrm{~kg}$ of binder, including cement, substitutes, and superplasticizer. Thus, this modeling involves a cradle-to-gate assessment of binder production instead of a full cradle-to-grave life cycle - the effects of mixing and curing, or other use (e.g., casting) on the GHG emissions are excluded. Solid carbon is considered a waste by-product of methane pyrolysis, and therefore all methane pyrolysis process and upstream emissions are assumed to be allocated to the $\mathrm{H}_{2}$ product.

In all scenarios, we assumed that a preheater/precalciner kiln was used for ordinary Portland cement production with a thermal requirement of $3.3 \mathrm{MJ} / \mathrm{kg}$ for clinkering. The fuel mixes in California, Florida, and Texas were all based on the United States average kiln fuel mix. More details regarding the cement production and the transportation and origins of the materials can be found in Supplementary Information.

\section{Acknowledgments}

This study is funded by Shell-Energy Biosciences Institute (CW296788). Support of NSF (DMR-CER grant \#1935604) is also acknowledged. Yeo-Jin Hong and Purvaansh Lohiya at Berkeley are thanked for experimental assistance. We also acknowledge Mark Staples and Sander van Bavel from Shell Global Solutions for their feedback on the manuscript.

\section{Supplementary Information}

The online version contains supplementary material available at https://doi.org/10.1557/s43577-021-00118-z.

\section{Open Access}

This article is licensed under a Creative Commons Attribution 4.0 International License, which permits use, sharing, adaptation, distribution and reproduction in any medium or format, as long as you give appropriate credit to the original author(s) and the source, provide a link to the Creative Commons license, and indicate if changes were made. The images or other third party material in this article are included in the article's Creative Commons license, unless indicated otherwise in a credit line to the material. If material is not included in the article's Creative Commons license and your intended use is not permitted by statutory regulation or exceeds the permitted use, you will need to obtain permission directly from the copyright holder. To view a copy of this license, visit http://creativecommons.org/licenses/by/4.0/.

\section{References}

1. S. Schneider, S. Bajohr, F. Graf, T. Kolb, State of the art of hydrogen production via pyrolysis of natural gas. Chem. Ing. Tech. 92(8), 1023 (2020)

2. B. Parkinson, P. Balcombe, J.F. Speirs, A.D. Hawkes, K. Hellgardt, Levelized cost of $\mathrm{CO}_{2}$ mitigation from hydrogen production routes. Energy Environ. Sci. 12(1), 19 (2019)

3. International Energy Agency (IEA), Hydrogen Projects Database (2020)

4. International Energy Agency (IEA), Coal 2019-Analysis and Forecasts to 2024 (2019)

5. P.J.M. Monteiro, S.A. Miller, A. Horvath, Towards sustainable concrete. Nat. Mater. 16(7), 698 (2017)

6. P.K. Mehta, P.J. Monteiro, Concrete Microstructure, Properties and Materials (McGraw-Hill, New York, 2017)

7. S.A. Miller, V.M. John, S.A. Pacca, A. Horvath, Carbon dioxide reduction potential in the global cement industry by 2050. Cem. Concr. Res. 114, 115 (2018)

8. M.C.G. Juenger, R. Snellings, S.A. Bernal, Supplementary cementitious materials: New sources, characterization, and performance insights. Cem. Concr. Res. 122, 257 (2019)

9. F. Sanchez, K. Sobolev, Nanotechnology in concrete: A review. Constr. Build. Mater. 24(11), 2060 (2010)

10. J. Plank, C. Schroefl, M. Gruber, M. Lesti, R. Sieber, Effectiveness of polycarboxylate superplasticizers in ultra-high strength concrete: The importance of PCE compatibility with silica fume. J. Adv. Concr. Technol. 7(1), 5 (2009) 
11. Standard Test Method for Amount of Water Required for Normal Consistency of Hydraulic Cement Paste (ASTM-C187, ASTM International, West Conshohocken, PA, 2016)

12. H.F.W. Taylor, Cement Chemistry (Thomas Telford Publishing, London, UK, 1997)

13. W. Zhang, R. François, L. Yu, Influence of load-induced cracks coupled or not with top-casting-induced defects on the corrosion of the longitudinal tensile reinforcement of naturally corroded beams exposed to chloride environment under sustained loading. Cem. Concrete Res. 129, 105972 (2020)

14. M. Stefanoni, U.M. Angst, B. Elsener, Kinetics of electrochemical dissolution of metals in porous media. Nat. Mater. 18(9), 942 (2019)

15. D. Marchon, P. Juilland, E. Gallucci, L. Frunz, R.J. Flatt, Molecular and submolecular scale effects of comb-copolymers on tri-calcium silicate reactivity: Toward molecular design. J. Am. Ceram. Soc. 100(3), 817 (2017)

16. D. Marchon, F. Boscaro, R.J. Flatt, First steps to the molecular structure optimization of polycarboxylate ether superplasticizers: Mastering fluidity and retardation. Cem. Concr. Res. 115, 116 (2019)

17. D. Marchon, S. Kawashima, H. Bessaies-Bey, S. Mantellato, S. Ng, Hydration and rheology control of concrete for digital fabrication: Potential admixtures and cement chemistry. Cem. Concr. Res. 112, 96 (2018)

18. V.C. Li, Engineered Cementitious Composites (ECC): Bendable Concrete for Sustainable and Resilient Infrastructure (Springer-Verlag, Berlin, Germany, 2019)
19. P.-C. Aïtcin, R.J. Flatt, Science and Technology of Concrete Admixtures (Woodhead Publishing, 2015)

20. M.J. Chinchillas-Chinchillas, V.M. Orozco-Carmona, A. Gaxiola, C.G. AlvaradoBeltrán, M.J. Pellegrini-Cervantes, F.J. Baldenebro-López, A. Castro-Beltrán, Evaluation of the mechanical properties, durability and drying shrinkage of the mortar reinforced with polyacrylonitrile microfibers. Constr. Build. Mater. 210, 32 (2019)

21. S. Ivorra, P. Garcés, G. Catalá, L.G. Andión, E. Zornoza, Effect of silica fume particle size on mechanical properties of short carbon fiber reinforced concrete. Mater. Des. 31(3), 1553 (2010)

22. B. Han, L. Zhang, C. Zhang, Y. Wang, X. Yu, J. Ou, Reinforcement effect and mechanism of carbon fibers to mechanical and electrically conductive properties of cementbased materials. Constr. Build. Mater. 125, 479 (2016)

23. X. Li, M. Li, Multifunctional self-sensing and ductile cementitious materials. Cem. Concrete Res. 123, 105714 (2019)

24. United States Environmental Protection Agency (EPA), Documentation Chapters for Greenhouse Gas Emission, Energy and Economic Factors Used in the Waste Reduction Model (WARM) (2019)

25. A.P. Gursel, Life-Cycle Assessment of Concrete: Decision-Support Tool and Case Study Application, PhD dissertation, University of California, Berkeley (2014)

26. K.H. Yang, E.A. Seo, S.H. Tae, Carbonation and $\mathrm{CO}_{2}$ uptake of concrete. Environ. Impact Asses. Rev. 46, 43 (2014) 